\title{
VIEJAS IDEOLOGIAS Y NUEVAS REALIDADES CORPORATIVISTAS
}

\section{Juan Martínez Alier}

En este artículo analizo las ideologías sobre la distribución de la producción entre grupos sociales y dejo para el final el interrogante sobre el significado del término producción. La palabra corporativismo, en tanto que ideología y práctica de un sistema estructurado de desigualdad ligado a la socialdemocracia, tal como lo planteo en este artículo, puede parecer una provocación. Es necesario explicar las razones por las que el mismo término puede aplicarse a la ideología del franquismo o del salazarismo y a la realidad de Estados como el español desde 1977 (hasta por lo menos 1983).

Podemos poner al régimen franquista como ejemplo de corporativismo estatal. No había libertad de asociación y era obligatorio estar encuadrado en un sindicato vertical que agrupaba a trabajadores y empresarios de una misma rama. Los partidos políticos no existían (excepto la Falange; después, Movimiento Nacional), y las Cortes eran una Cámara corporativa (pese a que algunos miembros tuvieran una teórica representación territorial).

Quisiera argumentar, de todos modos, que «corporativismo estatal» es una expresión contradictoria, por lo menos en el caso del Estado español franquista. Acababa de librarse una guerra civil que fue una guerra de clases; la conciencia de clase era muy fuerte. ¿Acaso el corporativismo estatal es una ideología sin realidad histórica? Quizá lo fue el peronismo en su primera época, ya que los sindicatos eran genuinos. No obstante, queda la duda de si otros 
intereses, como los de los exportadores agrarios, pudieron tener representantes auténticos.

Para contestar a la pregunta de si el franquismo es o no corporativismo estatal auténtico, voy a analizar la determinación de los salarios y de las condiciones de trabajo. Entre 1939-1958, tanto los salarios como las condiciones de trabajo, para cada ramo de la economía, fueron determinados por el gobierno. Esto no significa que no hubiese habido huelgas u otras formas de resistencia que desembocaran en acuerdos específicos de empresa (a pesar de que las huelgas estaban tipificadas como delito en el Código Penal). En general, las regulaciones estatales se cumplían. No olvidemos la terrible derrota que sufrió la clase obrera (con ejecuciones masivas hasta tres o cuatro años después de finalizada la guerra); ni olvidemos tampoco la crisis económica: los salarios reales no alcanzaron los niveles de antes de la guerra hasta la mitad de los años 1950, en la industria, y hasta los inicios de 1960, en la agricultura.

Trabajadores y empresarios pertenecían formalmente a los sindicatos verticales. Los dirigentes de estos «sindicatos» eran designados por el gobierno y tenían que ser obligatoriamente miembros de la Falange, tanto los de la parte obrera como los de la parte empresarial. Las presiones de los empresarios sobre el gobierno no se canalizaban siempre a través de los sindicatos verticales, sino a través de las Cámaras de Comercio y de Industria, que continúan existiendo. En resumen, un sindicato cuyos dirigentes son nombrados por el Estado es un sindicato muerto, y lo mismo podemos decir de la organización patronal.

En 1958, la introducción de una negociación colectiva a diferentes niveles, centro de trabajo, empresa, nivel local, provincial y «nacional», va a poner en evidencia las contradicciones del «corporativismo estatal». Fue entonces, cuando a Franco le quedaban todavía veinte años de vida, cuando empezó el período de la «primacía de la economía» y de los economistas, que todavía dura. La teoría económica va a servir de ideología de la armonía social de modo más convincente (incluso para los trabajadores) que el viejo corporativismo. La pérdida de la influencia de la Falange y el auge de grupos católicos como el Opus Dei y la ACNP fueron paralelos a estos cambios de ideología.

Los católicos creían en el principio de «subsidiariedad» del Estado. Antes de la guerra civil pensaban en la posibilidad de existencia de unos auténticos sindicatos obreros católicos, que llevaran a cabo convenios colectivos dentro de las «corporaciones» con los empresarios. El Estado no tenía por qué regular en detalle los salarios y las condiciones de trabajo.

En 1936, los católicos hubieran preferido, sin lugar a dudas, una victoria electoral de la CEDA, o un golpe de Estado militar, a la larga guerra civil (que podían haber perdido). Habrían prohibido la CNT y, probablemente también, la UGT (que en 1934 había dado un giro hacia la izquierda), y habrían disuelto el Parlamento y organizado una Cámara corporativa. Los falan- 
gistas, que no creían en absoluto en el principio de «subsidiariedad», fueron ganando ascendencia durante la guerra. Todos ellos van a colaborar en la creación del «nuevo Estado», y los católicos tendrán que pagar el precio de vestir el brillante uniforme de la Falange.

En 1946, Larraz, ministro de Hacienda y miembro de la ACNP, se quejaba del «maltrato» (de corta duración) de los aliados al régimen de Franco. En aquellos momentos de pasión, muchos creían que un régimen corporativo era una idea que pertenecía al totalitarismo, condenable a priori. Algunos incluso querían hacer del régimen corporativo una especie de criminal de guerra. ¡Pura ignorancia! Un régimen corporativo daba forma orgánica a la estructura profesional de la sociedad, era un producto natural y espontáneo de la vida social que el Derecho positivo no podía rechazar; había que hacerlo coincidir con el bien común. Tras el desmantelamiento que el liberalismo había hecho desde el siglo xvirI de sus instituciones y principios sociales, el corporativismo fue defendido por personas de orígenes muy diversos. Por ejemplo, Sismondi, los primeros socialistas, la escuela socialcatólica desde Mun hasta ahora. La transformación del sindicalismo revolucionario en algo constructivo, que propuso Duguit, era también corporativismo, y lo encontramos también entre los «guildistas» ingleses (prefacio a Severino Aznar, 1946, pp. XI-XII).

Severino Aznar fue uno de los ideólogos del corporativismo católico más importantes del Estado español (como muestra el excelente libro de J. J. Castillo sobre los campesinos castellanos, base social y sólida de este movimiento). No solamente citaba a Ketteler y Vogelsang, De Manning y Decourtis, Toniolo, Hitze y Lorin, sino también el prefacio a la segunda edición de la Division du Travail Social, de Durkheim: «Toda una escuela sociológica y positivista científica que tiene admiradores en todo el mundo culto ha llegado a las mismas conclusiones que desde hace medio siglo están difundiendo los reformadores sociales católicos. Durkheim, que no tiene ninguna relación positiva, y que es hoy el mayor prestigio sociológico de Francia, llegó a las mismas conclusiones que Hitze, sacerdote, uno de los más ilustres campeones del régimen corporativo en Alemania; Duguit, que siente por el catolicismo una hostilidad siniestra de hugonote, coincide con aquel católico excelso que, para mala ventura del catolicismo social, emigró ha poco de la vida, con Henri Lorin» (op. cit., 1946, p. 214).

Hubo influencia de alemanes como Adam Heinrich Müller, Franz von Baader, Ketteler, Hitze; de austríacos como Volgelsang y Seipel; pero también de Durkheim y Dunguit, que lo introdujo en la Península Ibérica A. Posada (que no era católico, si no me equivoco), que tradujo y presentó La Transformación del Estado (1909). Dos ideas de Dunguit influyeron profundamente en la ideología corporativista: la concepción de la propiedad como una «función social» (la encontramos también en la Constitución española de 1978) y la idea de que «la lucha de clases podría suavizarse si se establecieran reglamentos contractuales que determinaran las relaciones entre 
clases» y, de este modo, el Estado, al ofrecer el marco legal de la negociación colectiva, podía colaborar a la desaparición de la amenaza del sindicalismo revolucionario, de acción directa (la Carta de Amiens es de 1907). Estos enfoques eran más útiles para enfrentarse a un sindicalismo revolucionario, basado en ideas tan peligrosas como «la propiedad es un robo» y el principio de acción directa, que la insistencia en el derecho de propiedad absoluto (de Derecho romano o de Derecho «natural», lo mismo da) y la posición liberal extremista contraria a las coaliciones de trabajadores.

Los católicos españoles hubieran preferido un corporativismo natural y espontáneo. Después de eliminar a tantos enemigos de clase, de prohibir los sindicatos obreros más arraigados (como la CNT y la UGT) y de dejar en la penumbra a las organizaciones empresariales, no tenían derecho a pensar que el sistema pudiera funcionar sin represión. El corporativismo estatal mató la base social de un corporativismo espontáneo.

La historia de la negociación colectiva después de 1958 muestra esta carencia de corporativismo social, incluso al nivel más elemental de las empresas y fábricas. La ley de convenios colectivos formaba parte de un grupo de medidas, tomadas entre 1958 y 1960 , en parte aconsejadas por la OECE (después $\mathrm{OCDE}$ ) y el Banco Mundial, orientadas a disminuir el intervencionismo estatal en la economía. Se podía encontrar una base ideológica para los convenios colectivos en el mismo pensamiento corporativista, aunque fueron vistos, sobre todo, como una manera de relacionar salarios y aumentos de productividad.

Después del plan de estabilización de 1959, la economía creció prácticamente sin pausas hasta 1975 . Hubo grandes movimientos de trabajadores entre sectores (es la época de los falsos aumentos de productividad en la agricultura, estudiados por Naredo), con emigración masiva hacia las ciudades y hacia Europa. El gobierno quería que los convenios colectivos se firmasen de manera descentralizada, reservándose la facultad de prohibir su puesta en práctica mediante el procedimiento de homologación (que ya no existe). El contrato podía ser devuelto a la mesa de negociación en caso de que implicara aumentos salariales que pudieran ser inflacionarios. Las negociaciones se llevaban a cabo en el sindicato vertical entre representantes de los trabajadores y de los empresarios.

El surgimiento y desarrollo de las Comisiones Obreras a partir de la negociación colectiva se ha explicado muchas veces. Era necesario conseguir representantes genuinos en las negociaciones, concretamente en el jurado de empresa (una especie de comité de trabajadores), parte de la estructura sindical oficial que negociaba en nombre de los trabajadores (Amsden, 1971). El procedimiento de asambleas masivas, que consideraban las propuestas y elegían delegados temporales para negociar el convenio, se desarrolló espontáneamente -estos delegados no siempre eran miembros del jurado de empresa-. Algunos empresarios aceptaron, incluso públicamente, este sistema paralegal, ya 
que de este modo podían llegar a acuerdos con representantes realmente responsables ${ }^{1}$.

La negociación colectiva a finales de los años sesenta y a principios de los años setenta se llevó a cabo, muchas veces, por medio de la acción directa e incluso con intervención de asambleas masivas de trabajadores. La razón estriba, por un lado, en la debilidad de los sindicatos oficiales, despreciados por los trabajadores a pesar de utilizarlos como refugio legal, y, por otro, por la dificultad de coordinación. Pese a que al gobierno no le gustaba lo que estaba sucediendo, veía a los convenios colectivos como un instrumento necesario para ligar aumentos de salarios con aumentos de productividad. Las cosas hubieran podido ser distintas. Por ejemplo, el viejo sistema de reglamentación central hubiera podido continuar con generosos incrementos en estos años de crecimiento económico, cuyas causas eran externas e independientes del grado de intervencionismo estatal. Sin embargo, se impuso un sistema de negociación colectiva descentralizado ${ }^{2}$.

El gobierno insistía en la necesidad de los convenios colectivos incluso en la agricultura latifundista. Los funcionarios debían informar continuamente a Madrid sobre los convenios colectivos realizados en cada pueblo. En los pueblos más militantes (que luego eligieron alcaldes de partidos a la izquierda del Partido Comunista), los trabajadores no participaban en las elecciones de los «sindicatos verticales»; además, en los años sesenta todavía no se atrevían a realizar asambleas ni a elegir delegados extralegales, ya que la represión era mayor que en las ciudades. Por tanto, no podía haber negociación de convenios. Este es un caso de carencia absoluta de acuerdos colectivos, incluso al nivel más elemental, a causa, precisamente, de la introducción forzosa del «corporativismo estatal».

Aunque la negociación colectiva podía defenderse desde premisas clásicas del pensamiento corporativista, la ideología que se utilizó fue la ideología derivada de análisis económicos ${ }^{3}$. Era posible la existencia de un nuevo corporativismo explícitamente basado en la primacía de la economía, como en

${ }^{1}$ La coordinación entre representantes obreros de distintas empresas y localidades era ilegal. Además, dentro de Comisiones Obreras habían enfrentamientos políticos. Poco a poco, el Partido Comunista fue asumiendo la dirección, hasta que a principios de los setenta los líderes comunistas de Comisiones Obreras fueron juzgados en Madrid y encarcelados, en diciembre de 1973 (precisamente el mismo día en que ETA mató al almirante Carrero Blanco); no fueron puestos en libertad hasta noviembre de 1975, después de la muerte del general Franco.

2 Otra especulación retrospectiva es la siguiente: si los viejos líderes de la CNT en el exilio, en vez de obstinarse en un sectarismo antisindicalista, disolviendo su organización residual, hubiesen puesto su nombre a disposición de las «comisiones obreras» espontáneas que surgían a principios de los setenta, seguramente el viejo sindicalismo revolucionario ibérico habría encontrado otra vez su lugar.

${ }^{3}$ Las políticas de rentas no apelan a nociones de justicia distributiva y conmutativa, ni al decorum de los distintos grupos sociales, sino a argumentos económicos, más idóneos para llegar a un consensus social. El vocabulario aristotélico continúa utilizándose (un salario digno, donde la dignidad depende del estamento social), aunque complementado por un vocabulario económico. 
la Inglaterra de Harold Wilson o en la Alemania Occidental de la «gran coalición» de 1967 y de la «acción concertada». No obstante, era imposible establecer un acuerdo corporativo central por falta de interlocutores válidos, especialmente del lado de los trabajadores. Los posibles interlocutores eran clandestinos o estaban en la cárcel, etc. Una política de rentas firmada por el sindicato vertical habría sido la burla de todos. Si la estructura de corporativismo estatal era incapaz de amparar a trabajadores y empresarios en las fábricas, resultaba todavía más inútil para un acuerdo general sobre salarios. Por tanto, el Estado tuvo que intervenir con el arbitraje obligatorio e incluso, algunos años, con decretos de congelación de salarios reales. El último de estos decretos, casi simultáneo a la muerte de Franco, no fue nada respetado.

Unos órganos teóricamente representativos, cuyos dirigentes eran nombrados por el gobierno, no tenían capacidad para establecer acuerdos firmes. Charles Anderson (1970) enfatizó la amplitud del debate económico en el Estado español de los años sesenta, pero no advirtió que un límite del «pluralismo autoritario" franquista era, precisamente, la imposibilidad de un acuerdo corporativo central con las organizaciones obreras. Situación completamente distinta de la decisión de los dirigentes sindicalistas franceses de negarse a participar en los pactos sociales, ya que en Francia no carecían de representación.

Así, pues, la cuestión de si la clase obrera estaba dispuesta a aceptar una política de rentas basada en directivas macroeconómicas no se aclararía hasta después de la muerte de Franco, ya que antes los trabajadores no tenían representantes en condiciones de poder dar una respuesta válida ${ }^{4}$.

\section{Corporativismo: una palabra conflictiva}

España (y Portugal, a pesar de que aquí la situación es distinta al existir un fuerte Partido Comunista "prosoviético») pasó a mediados de los años setenta de un sistema político corporativista a un sistema pluralista, parlamentario, precisamente en los años en que en otros países europeos empezaba un debate científico sobre "neocorporativismo». Se pasó de una situación en la que había una sola Cámara corporativa y no existían los partidos políticos (o solamente uno) a una situación con partidos políticos que compiten entre ellos en las elecciones parlamentarias. De la asociación obligatoria en corporaciones profesionales (llamados sindicatos verticales en España) se pasó a una situación de libertad de asociación y de participación en los diversos sindicatos de trabajadores y organizaciones empresariales. Antes de 1973, nunca pensé que el «viejo» y el «nuevo» corporativismo tuvieran suficientes elementos comunes para llevar el mismo nombre. Me lo sugirió The New Infla-

4 Si en Polonia el gobierno consiguiera aislar a los radicales (que están encarcelados), podría quizá llegar a un acuerdo sobre salarios y política económica entre Solidarnosc y las burocracias del partido y del ejército (que hacen de empresarios). El pluralismo es, ciertamente, limitado; sin embargo, es casi suficiente para conseguir este tipo de acuerdos. 
tion, de Aubrey Jones, a pesar de que el término «corporativismo» no aparece. Antiguo ministro conservador (de la tendencia wet, como el mismo Heath), Aubrey Jones fue nombrado por Wilson para dirigir el Price and Incomes Board, un organismo consultivo cuya misión consistía en juzgar si los acuerdos de los convenios colectivos sobre salarios eran inflacionistas y determinar criterios sobre diferencias salariales. Jones llegó a la conclusión de que faltaban criterios económicos para establecer si los aumentos salariales determinados por la libre y descentralizada negociación colectiva tradicional en Gran Bretaña eran o no excesivos. Propuso la creación de una Cámara corporativa (sin utilizar este nombre) donde los representantes de ambos bandos pudieran decidir una política de rentas.

El supuesto (durkheimniano) implícito era que habría un grado suficiente de consensus, quizá porque los actores sociales serían capaces de entender el imperativo del equilibrio de la balanza de pagos. Era una suposición optimista; hubo quienes proponían hacer un análisis de clase de la balanza de pagos (¿.por qué no?). Parecía, pues, que la inexistencia de un criterio teórico-económico capaz de juzgar la distribución del ingreso podría llevar tanto hacia una estrategia sindicalista propuesta, por ejemplo, por Glyn y Sutcliffe (1971) como, paradójicamente, hacia un revival corporativista.

A pesar de haberme percatado de la ofensiva del neoliberalismo económico, hasta el triunfo de Thatcher no creí que la fe en el mercado resucitara de forma tan espectacular ( $y$ paradójica, al mismo tiempo, al coincidir con la nueva conciencia de que el mercado es incapaz de asignar recursos no renovables entre generaciones).

Además, antes de llegar a la conclusión de que el neocorporativismo explícito era la nueva ideología capitalista y socialdemócrata (me sorprendió la propuesta de la tercera Cámara corporativa en Gran Bretaña), había que haber discutido hasta dónde el keynesianismo podía ser útil todavía como soporte ideológico de prácticas corporativistas informales. Por ejemplo, la noción de Kaldor según la cual el crecimiento depende de las ganancias (ahorradas), que son la fuente de la inversión, y que una determinada tasa de crecimiento deseado depende de una determinada tasa de ganancias (suponiendo una relación incremental dada capital/producto), fue un soporte de los acuerdos colectivos, sin necesidad de ideología «durkheimniana». La eficacia de este argumento puede depender actualmente del prestigio intelectual que alcance la crítica ecológica de las teorías del crecimiento.

El libro de Aubrey Jones llevaba por subtítulo «La política de los precios y de los ingresos». Para este politicólogo, el corporativismo consiste en un sistema extraparlamentario de representación y de intermediación de intereses organizados. En el «viejo» corporativismo, el propio Parlamento quedaba sustituido por una Cámara corporativa, mientras que en el «nuevo» corporativismo una de las cuestiones más debatidas es el sistema de representación polí- 
tica a través de los partidos y el sistema de intereses organizados ${ }^{5}$. Para un economista, corporativismo significa, sobre todo, determinación de precios y de ingresos fuera del mercado.

Si extraparlamentario resulta una expresión grotesca en un régimen parlamentario, "extramercado" es casi un insulto en una economía de mercado generalizado. Dado que la teoría económica (tanto la microeconomía ortodoxa como la macroeconomía keynesiana de corto y largo plazo, aunque no la economía ecológica marxiana o sraffiana, o la economía ecológica de GeorgescuRoegen) ha servido para legitimar la distribución desigual del ingreso, no podemos pensar que los precios y los ingresos sean una cuestión política. Por estas razones, nos encontramos con que el corporativismo, con sus connotaciones extraparlamentarias y extramercantiles, no es la ideología explícita de casi nadie. Es una realidad sin ideología.

El término socialismo ha mantenido siempre una cierta connotación favorable a la igualdad, mientras que el término «corporativismo» denota, precisamente, un sistema que estructura permanentemente la desigualdad, así como la ideología que defiende este sistema. El rechazo del término «corporativismo» por los practicantes socialdemócratas del neocorporativismo muestra los problemas de legitimación de estas prácticas ${ }^{6}$.

Los conceptos utilizados para analizar la realidad política son, en sí mismos, componentes de la realidad política. El éxito en la introducción de un término político depende de la aceptación general o de un sector social, y puede influir sobre la realidad política. La terminología política es, en sí, una cuestión de distribución del poder (Connolly, 1974, p. 80). La distinción entre términos descriptivos (o analíticos) y términos normativos no se adapta bien al lenguaje de la ciencia política. La lucha política es, también, una lucha por conceptos y términos, de la que «corporativismo» es un ejemplo evidente.

El término «corporativismo» se ha utilizado en diferentes sentidos, marcados por los adjetivos «autoritario», «estatal», «viejo», por un lado, y «libe-

S Quizá el único caso de una especie de Cámara corporativa en países con régimen parlamentario ha sido el Consejo Económico y Social de los Países Bajos. Resulta difícil reconciliar la existencia de una Cámara corporativa con la teoría de una democracia pluralista. A los autores austríacos les gusta decir que, en Viena, la Comisión Paritaria no tiene local, ni siquiera teléfono.

- Para interpretar la transición política que se avecinaba en el Estado español propuse muchas veces la idea de un neocorporativismo. En octubre de 1975, invitado por el Círculo de Economía a una de las reuniones de la Costa Brava, donde casi todos defendían un pacto social, dije que a éste se le podía llamar corporativismo, lo que me hizo merecedor de una regañina por parte de Ferrer Salat y ningún apoyo del resto. Un diario de Madrid (Intormaciones) hizo una pequeña alusión a lo ocurrido. En Cuadernos de Ruedo Ibérico publiqué un artículo sobre el Pacto de la Moncloa. Hablaba de neocorporativismo, a pesar de no haber leído todavía a Schmitter, Lehmbruch, Panitch o Winkle. Menos indignación y mayor conocimiento de la discusión internacional sobre el tema lo habría mejorado. Entre 1978 y 1983 he publicado otros artículos en periódicos y revistas como Bicicleta, Solidaridad Obrera y Egin. En julio de 1981 mandé un artículo a El País, publicado en diciembre de 1981, preguntando por qué se había importado la terminología neocorporativista («concertación») sin importar simultáneamente el debate: ¿acaso era demasiado fuerte? El artículo no tuvo respuesta. 
ral», «social», «nuevo», por el otro. Esta diferencia la encontramos en Maiolesco (como señala Schmitter en su brillante artículo de 1974) y en la tradición intelectual socialdemócrata (por ejemplo, en las tesis de Otto Bauer en 1933-34, sin que Bauer y Maiolesco se citaran mutuamente). Estos dos tipos de corporativismo se distinguen, además, en que el «viejo» corporativismo era simplemente una doctrina, una ideología, mientras que el «nuevo» corporativismo es una realidad en busca de una ideología que no sea explícitamente corporativista.

El caso español desde 1977 es un ejemplo de corporativismo liberal parlamentario - acuerdos tripartitos sobre rentas negociados fuera del Parlamento y del mercado, preservando, de todos modos, la desigualdad social $-\mathrm{y}$, desde luego, ninguno de sus políticos, líderes obreros o líderes empresariales se confiesa partidario de una doctrina corporativa. Linz y Maravall estaban informados de la discusión internacional sobre corporativismo y, no obstante, ninguno de los dos $(1981,1982)$ utilizó este concepto al analizar la estructura político-económica emergente, ni la discutieron ni la rechazaron. Werner Lang (1981) preveía erróneamente el fin de los pactos sociales, pero discutió el Pacto de la Moncloa en el debate internacional sobre neocorporativismo.

En la práctica, ocurren episodios periódicos con "ruido de sables» que tienen efectos políticos. Además, la Constitución de 1978 otorga al ejército (en el artículo octavo, de interpretación ambigua) un papel poco frecuente en otros países occidentales parlamentarios. La amenaza de este órgano del Estado ha estado presente (según manifestaciones de los actores) en las mesas de negociación de casi todos los "pactos sociales» desde 1977. Una definición del nuevo régimen español, desde 1977 hasta por lo menos 1983, podría ser la de corporativismo liberal parlamentario con fuerte presencia militar, no solamente como «corporación» con intereses profesionales propios, sino con un proyecto político propio en lo que se refiere a la unidad del Estado español frente a los separatismos nacionalistas.

Aunque "corporativismo» fuese una definición adecuada y con valor analítico, resulta ser un concepto demasiado «fuerte»: su utilización es una cuestión política. Los términos «Estado corporativo», «economía corporativa» y, en general, "corporativismo» han sido utilizados más a menudo como insulto que como elogio en el debate internacional de la década de los setenta ${ }^{7}$. Sin embargo, algunas veces se ha usado también de modo elogioso; por ejemplo, al referirse a países ibérico-latinos (Wiarda, Pike, 1974), a pesar de que en

7 El líder de la UGT, Nicolás Redondo, explicaba en El País, el 11 de junio de 1983, que los sindicatos podían optar por una de estas tres vías: actuar de modo que colaborasen en la implantación de una solución política neoliberal, de claro contenido antisindical; decidirse por una política de grandes acuerdos, con sacrificios y contrapartidas equilibradas, y la negociación libre, descentralizada por sectores, que, inevitablemente, daría lugar a prácticas «corporativistas». Encontramos aquí una clara defensa del corporativismo, reservando el término - a la moda italiana y francesa- para actuaciones que en la literatura académica no tienen un nombre establecido. Lo que en un lugar se llama free collective bargaining, con una connotación en general positiva, puede llamarse en otro lugar BetriebEgoismus, como insulto. 
uno de estos países (si podemos clasificar al Perú de ibérico-latino) Julio Cotler fue deportado por criticar al régimen militar que, desde 1971, trataba de construir un Estado corporativo. Un ejemplo de utilización elogiosa, en el International Herald Tribune de 21 de junio de 1977, decía que las socialdemocracias alemana y británica se dirigían hacia la creación de un nuevo tipo de Estado corporativo basado en la colaboración tripartita de gobierno, sindicatos y empresarios. Seguramente, un periódico de origen europeo no hubiera utilizado este término de una manera tan inocente. Es evidente que las socialdemocracias alemana y británica no se proponían sustituir los Parlamentos por Cámaras corporativas. Quizá la colaboración tripartita, con el fin de llegar a acuerdos (extraparlamentarios y extramercado) sobre salarios y sobre materias de política económica, podría describirse no como un sistema corporativo, sino como una estructura corporativa dentro del sistema políticoeconómico general (según Panitch, Kastendiek).

En un sistema corporativista, o cuando existen estructuras corporativistas, la defensa organizada de los intereses (que permite hablar de corporativismo de los médicos o de los PNN, o de los obreros de tal o de cual empresa) desemboca en acuerdos generales, normalmente con la intervención del Estado. Así, el Pacto de la Moncloa de 1977 representó el primer momento del neocorporativismo hispánico. A diferencia de los pactos sociales posteriores, no los firmaron los representantes de los sindicatos ni los representantes de los organismos empresariales, porque la CEOE todavía no estaba consolidada y porque en los primeros gobiernos postfranquistas había presencia muy directa de los grandes empresarios; por otro lado, los líderes de Comisiones Obreras y de UGT eran miembros del Parlamento, y cuando el Pacto de la Moncloa, firmado fuera del Parlamento, se debatió, con una celeridad meteórica, en el Parlamento, no encontró oposición en ninguno de los dos sindicatos. Buena parte de los trabajadores estaban en contra (o, simultáneamente, en contra y a favor, como señala Pérez Díaz, 1979), lo que explica la actitud poco entusiasta de los líderes de la UGT. La campaña contra el pacto social de los partidos de izquierda de antes de las elecciones de junio de 1977, y la tradición de Comisiones Obreras de negociación colectiva descentralizada, aconsejaron complementar el acuerdo corporativo sobre normas salariales con un acuerdo entre partidos políticos, fuertemente legitimados por la gran tasa de participación del gobierno) de las actuaciones del sistema de partidos, ya separado el acuerdo entre intereses organizados (muchas veces incluso con la participación del Gobierno) de las actuaciones del sistema de partidos, ya que en una economía de mercado el Parlamento no tiene por qué intervenir en una negociación de salarios y de condiciones de trabajo.

En un sistema de corporativismo estatal resulta imposible realizar acuerdos corporativos genuinos. Sin embargo, en el Estado español actual, pese a la débil implantación de los sindicatos (medida por el número de afiliados), existen intermediarios válidos. El grado de cumplimiento de los pactos so 
ciales realizados desde 1977 es muy alto. Lo cual no significa que los trabajadores estén de acuerdo; yo hablaría más bien de una mezcla de acuerdo y desacuerdo característica de la "conciencia dual» de los trabajadores en países como el nuestro o más pobres.

De todos modos, ¿cuáles son las bases ideológicas de estos acuerdos? Difícilmente podemos decir que la ideología subyacente a los pactos sociales sea la de evitar un golpe de Estado de los militares, pese a las frecuentes llamadas a la necesidad de "consolidar la democracia». Esto no sirve como ideología, o, en todo caso, como única ideología, ni aquí, ni en brasil, ni en Argentina. Lo que hay que preguntarse es: ¿por qué en los años 1975-77 los sindicatos emprendieron una orientación macroeconómica y todavía no la han abandonado?; ¿es probable que esta orientación resista un prolongado período de falta de crecimiento? Si la macroeconomía, tanto de corto como de largo plazo, está cada vez más cuestionada, ¿podemos esperar una resurrección de doctrinas corporativistas basadas en la armonía social más que en argumentos económicos? ¿Las doctrinas de armonía social son compatibles con las tradiciones intelectuales de sindicatos que se llaman socialistas y comunistas y, sobre todo, con la imagen de sociedad dividida en clases que la mayoría de trabajadores tienen aquí? ¿Acaso arraigará entre los actores sociales la nueva ideología de los acuerdos contemporáneos como scambio politico y rational choise?

\section{La legitimación de la desigualdad permanente}

A partir de las revoluciones liberales, la representación política se supone territorial más que corporativa. Todos los ciudadanos de una circunscripción, y no sólo unos determinados grupos, eligen a sus representantes. Edmund Burke se escandalizaba por la composición del Tercer Estado de la Asamblea Nacional, en la que no se detectaban restos del llamado «interés natural de la propiedad agraria» (1790, p. 132). Thomas Paine, por el contrario, elogiaba la moción del Abbé Sièges por la que el «Tiers Etat o Comunes se declararon representantes de la Nación; los dos órdenes no podían considerarse otra cosa que diputados de corporaciones y sólo podían tener voz deliberadora al reunirse como representantes nacionales» $(1791, \mathrm{p}$. 127).

La teoría política liberal denomina "grupos de presión» a los intereses organizados, y lamenta el lobbyng que hacen cuando quieren influir en los parlamentarios ${ }^{8}$. El fundamento de un sistema neocorporativista consiste en

- Un término recién descubierto en la transición política española ha sido el de poder fáctico. No ha sido frecuente llamar poder fáctico a las organizaciones empresariales, a las organizaciones agrarias, a los sindicatos, porque han tenido menos poder que la Iglesia, el Ejército y la Banca y porque su poder parece más compatible con el sistema liberal. $\mathrm{Si}$ no se negocian los precios agrarios existe el peligro de que las organizaciones agrarias negocien con acción directa, sacando tractores a las carreteras. Con la Banca las cosas 
que los intereses organizados dejan de tener este carácter sospechoso de «grupos de presión» para convertirse, en un vocabulario lírico, en sozialpartners, como se autodenominan las organizaciones empresariales $y$ sindicales en Austria.

Una diferencia básica entre el viejo y el nuevo corporativismo consiste en hacer más auténtica la representación de los intereses sociales. Además, el nuevo corporativismo se diferencia, también, en que su ideología no es la armonía social per se, sino la necesidad de armonía para conseguir el crecimiento económico, en un marco de macroeconomía keynesiana, tanto a corto como a largo plazo.

Si en los próximos años la teoría del crecimiento económico pierde credibilidad, el argumento de restringir los aumentos salariales para que aumente la inversión perderá también toda su fuerza. Se podría proponer una economía sin crecimiento en una sociedad estamental; sin embargo, este tipo de corporativismo difícilmente sería aceptado por la socialdemocracia, ya que se basa en doctrinas de armonía social y en la colaboración de grupos de ciudadanos desiguales con «funciones sociales» permanentemente diferenciadas, y no en las doctrinas económicas en que se fundamenta actualmente ${ }^{9}$. Se podría quizá llegar a acuerdos de moderación salarial y de desigualdad permanente a cambio de mayor voz para las organizaciones obreras en la administración de la economía. Es una vieja idea que en la tradición socialdemócrata se llama «democracia económica» o «democracia industrial». Aquí cabe recordar las propuestas de Otto Bauer en 1933 y 1934, al explicar que la «democracia económica» y la «democracia industrial» eran términos sinónimos de «corporativismo autorregulado» ${ }^{10}$.

Otto Bauer escribió que la lucha de clases en Austria pasaba, en aquella época, por la interpretación de la Quadragessimo Anno. Pese a que el Papa elogiara al fascismo, existía una diferencia fundamental entre el corporativismo fascista (con funcionarios nombrados por el gobierno o el partido, sin libertad de asociación y sin derecho de huelga, sin partidos políticos y sin Parlamento)

funcionan de forma más sutil: si no se negocian los aumentos de coeficiente de liquidez, ¿qué podría suceder? ¿Qué presión podría ejercer directamente este grupo de presión?

${ }^{9}$ El corporativismo antiguo no necesitaba una ideología del crecimiento. Un ejemplo de ello es el salazarismo, por lo menos hasta bien avanzada la década de los sesenta (Manuel dE LUCENA, $A$ evoluçao do sistema corporativo portugués. O Salazarismo, Perspectivas e Realidades, Lisboa, 1976).

${ }^{10}$ Bauer, artículos en Arbeiter-Zeitung, 1933; en Werkausgabe, vol. 7, pp. 496-517, y «Klassenkampf und Ständeverfassung», Der Kampf, enero 1934; Werkausgabe, vol. 9, p. 341. Existe una explicación detallada, en inglés, de las propuestas de Otto Bauer a Charles A. Gulick, Austria. From Habsburg to Hitler (University of California Press, Berkeley, 1948, vol. II, pp. 1222-1229), donde Berufständische Selbsverwaltung está traducido por occupational-estates self-management, reservando el término corporativismo para el Italian corporative system. Esto resulta un poco ridículo porque en alemán se puede jugar con el término germánico y el término latino, mientras que en inglés el término germánico no existe. Occupational-estates self-management significa, en buen inglés, corporatist self-management. 
y lo que ahora denominamos «corporativismo liberal», que Bauer llamó berufsändische Selbsverwaltung (autoadministración o autorregulación corporativa), un concepto similar al de "capitalismo organizado», de Hilferding, o al de «democracia industrial» o "económica». Capitalistas y trabajadores colaboran, por medio de sus organizaciones, en unas instituciones similares a las surgidas de la negociación colectiva (Tarifgemeinschaften). No sólo se limitan a cuestiones de salarios y de condiciones de trabajo, sino que pueden determinar, por ejemplo, la producción y precios de cada sector económico.

Bauer pensaba que el «corporativismo estatal» (al que llamaba korporationensystem italiano) acabaría con el «corporativismo social». Esperaba que los católicos estuvieran de acuerdo con ello por el principio de subsidiariedad del Estado. No discutió la cuestión del Parlamento versus Cámara corporativa. $\mathrm{Su}$ análisis incluye un excelente sumario de las corrientes de pensamiento corporativista, hasta con un comentario sobre el sindicalismo revolucionario de Pelloutier y Grifoulhes. Se basa en una visión histórica del desarrollo del capitalismo monopolista, lo que le permite decir que ya no es posible la existencia de liberales económicos genuinos. En Austria, después de la primera guerra, tanto los trabajadores como los industriales y los banqueros perdieron poder frente a la aristocracia, los burócratas y los generales; entre trabajadores y capitalistas, en otoño de 1933, había todavía una situación de equilibrio, Gleichgewitcht. Así, pues, la administración corporativa, sinónimo de «democracia económica» o «industrial», no significaba de ningún modo un camino hacia el socialismo, que las circunstancias hacían inviable. En aquel momento, en vez de utilizar viejos términos de capitalismo organizado, democracia industrial o económica, se prefería el término corporativo - para defender a la socialdemocracia ante el inminente ataque armado de los católicos- y tranquilizar al Papa de Roma. El término «corporativismo» denota un sistema permanente de desigualdad. Por ese motivo, la socialdemocracia prefiere términos como «democracia económica» y «concertación» para legitimar las prácticas neocorporativistas. En 1933, Bauer eligió una terminología contraria.

La actitud de los sindicatos que realizan pactos sociales se ha intentado «explicar» en términos de rational choise (como Peter Blau, Brian Berry) o de scambio politico (como Pizzorno). Colin Crouch (1982) parte de la premisa de que lo que interesa a los trabajadores es aumentar los salarios y mejorar las condiciones de trabajo dentro de un marco capitalista. Los sindicatos pueden estar dispuestos a intercambiar restricciones salariales por mayor influencia sobre la asignación de fondos de inversión en la administración de las empresas. Renuncian precisamente al logro de salarios más altos a cambio de mayores dosis de «democracia industrial» o de «democracia económica». La elección es racional porque intercambian unas dosis de unos objetivos por unas dosis de otras mejoras.

Lo que los teóricos del rational choise y los apologistas de los pactos so- 
ciales creen explicar es la renuncia a los objetivos economicistas (no a hipotéticos objetivos revolucionarios que se supone que los trabajadores no tienen). Los trabajadores piden mayores salarios a las empresas no con ánimo de reducir las ganancias a cero, ni de hundir al capitalismo; aunque no lo piden con el fin de ayudar al capitalismo. Sin embargo, los acuerdos corporativistas introducen un nuevo objetivo: ayudar al capitalismo. El procedimiento determina los objetivos. No hay una elección racional entre objetivos diversos, cambiando un poco de uno a otro. Lo que hay, con la introducción de los acuerdos corporativos, es un cambio de objetivos en los sindicatos, que antes no se proponían ayudar a consolidar el capitalismo. Sería preciso explicar este cambio, cosa que los teóricos del rational cboise no hacen. Esta parodia de microeconomía no entra en el análisis histórico de los valores y de las preferencias. Observan «preferencias reveladas» y las «explican» tautológicamente.

Los sindicatos tienen objetivos contradictorios e incompatibles, y no hay trade offs basados en elección racional, sino movimiento histórico hacia adelante, hacia atrás, de lado. La coherencia en las elecciones es un supuesto de la teoría económica respecto de los individuos hipotéticos de la microeconomía, no es una realidad de los actores sociales, cada uno de los cuales puede tener una diversidad de objetivos simultáneos irreducibles a una sola dimensión. Si abandonamos la unidimensionalidad utilitarista, está claro que no sólo los sindicatos, sino los individuos, pueden ser incoherentes en sus elecciones.

El corporativismo cristiano, el corporativismo durkheimniano, el que propuso Otto Bauer, el corporativismo keynesiano-socialdemócrata y el corporativismo del scambio politico y rational choise, tienen en común la desconfianza en los resultados del mercado y el objetivo de armonía social.

Existen diversas maneras de oponerse al corporativismo. Una es la denuncia del corporativismo como un sistema estructurado de desigualdad que lo hace condenable desde posiciones ideológicas igualitaristas. Por ese motivo, a los que usan el nombre de «socialistas» les molesta el uso del término corporativismo, no pueden decir que están a favor de la desigualdad permanente, y utilizan eufemismos. Pero también se puede condenar el corporativismo de los pactos sociales desde la derecha, como sucedió en Inglaterra en los años que precedieron al triunfo de Thatcher (dentro del mismo Partido Conservador podemos encontrar posturas corporativistas, como las de Aubrey Jones, 1973, y anticorporativistas, Keith Joseph, 1976).

Uno de los primeros ataques antisindicales y neoliberales contra el neocorporativismo lo encontramos coherentemente en Hayek (1960, pp. 282-283). Dice así:

«En los países en que ha habido tendencias inflacionarias desde hace algún tiempo, podemos observar peticiones cada vez más frecuentes de una "política de rentas general...". Esto no es más que el resultado inevitable de las actuaciones de los sindicatos, dirigidas por el deseo de que los salarios se determinen por algún concepto de "justicia" en vez de por las fuerzas del merca- 
do... Cuando ya no podemos fiarnos de la determinación impersonal de los salarios del mercado, la única manera de conservar un sistema económico viable es que los salarios se determinen de forma autoritaria por el gobierno. Esta determinación ha de ser necesariamente arbitraria, ya que no hay estándares objetivos de justicia que puedan ser aplicados. Como cualquier otro precio, las tasas de salarios que son compatibles con una oportunidad abierta a todos para encontrar trabajo no se corresponden con ningún mérito que se quiera juzgar ni con ningún estándar de justicia independiente, sino que dependen de condiciones que escapan al control... Bajo este sistema, los sindicatos tendrán que escoger entre convertirse en instrumento volúntario de la política del gobierno o desaparecer totalmente. La primera alternativa es más probable, ya que permite que la burocracia sindical existente conserve su posición y algo de su poder personal. Sin embargo, para los trabajadores supondrá una subordinación completa al control de un Estado corporativo... La posición actual de los sindicatos no puede continuar, ya que los sindicatos sólo pueden existir en una economía de mercado y están haciendo todo lo posible por destruirla.»

¡No todos los austríacos tienen tendencias corporativistas! Hayek cree que los sindicatos son una interferencia extraña en la economía de mercado, donde los individuos hacen transacciones. No son un producto histórico, irremediable, de la lucha de clases ${ }^{11}$. La predicción, hecha en los años de pleno empleo, de que los sindicatos pondrían dificultades al sistema capitalista y que la alternativa era introducir pactos sociales generales, frente a la negociación colectiva fábrica a fábrica, fue muy acertada ${ }^{12}$. Esta predicción de que el capitalismo de mercado con sindicatos fuertes y pleno empleo no puede funcionar y tiende a convertirse en un capitalismo corporativista ya la hizo Kalecki en 1943. El era contrario a la abolición de los sindicatos. Predijo la creación cíclica del paro para mantener los sindicatos a raya. Kalecki (como Joan Robinson) creía, no obstante, en la posibilidad de una teoría puramente económica del crecimiento. Los keynesianos de izquierda (más kaleckianos y marxistas que keynesianos) no se plantearon la cuestión del agotamiento de los recursos y, por lo tanto, no nos sirven de guía científico-política.

Ahora bien, si la ilusión del crecimiento fracasa, ¿de qué manera podría legitimarse la desigualdad? ¿A través de un neocorporativismo más durkheim-

"La existencia misma de los sindicatos se puede explicar con reduccionismo individualista, como, por ejemplo, ha querido hacer Mancur Olson. La conciencia de clase, los objetivos colectivos no juegan ningún papel: al contrario, individuos racionales estudian las ventajas que podrían sacar de su incorporación y de su participación en los sindicatos; no existen actores sociales, existen coaliciones de individuos racionales.

${ }_{12} \mathrm{El}$ neoliberalismo esperó que llegara la crisis: si, en Inglaterra, Thatcher puede estar contra el incomes policy, después de introducir el mayor desconcierto entre la izquierda, dividida entre partidarios y contrarios de un pacto social, es precisamente gracias a que el mercado laboral funciona mucho «mejor» cuando hay unos cuantos millones de parados. En el Estado español existen empresarios que opinan que ya no es necesario realizar pactos sociales. 
niano que keynesiano, gestionado por la socialdemocracia, que utilizara términos como «concertación», «democracia económica» y, quizá, hasta «armonía social»? ¿O será por el renacimiento del darwinismo social individualista bajo la gestión política neoliberal? La falta de legitimación puede llevar, por un lado, a la violencia abierta y, por otro, a la resignación tanto en el interior del Estado como internacionalmente. Frente a estas perspectivas se puede luchar con la antigua arma de la rabia de los pobres contra los ricos, bien razonable, o con instrumentos teóricos que la economía ecológica proporciona para aproximarnos a una «historia del futuro» factible y deseable.

Una economía sin crecimiento, o con decrecimiento, no exige como cuestión lógica una distribución más igualitaria. El ecologismo, que puede cuestionar las teorías del crecimiento económico, no siempre es de izquierdas, porque unas veces es «optimista» con respecto al crecimiento (se diferencia de la economía en que habla de flujo de energía y de ciclos de materiales, en vez de hablar de inversión o de producción, pero no precisamente por su grado de (optimismo») y otras veces va del brazo del socialdarwinismo.

\section{La crítica ecológica. Neocorporativismo keynesiano-socialdemócrata}

Consideremos una expresión como «la producción de petróleo». El ritmo de la extracción del petróleo es mucho más rápido que el ritmo de su formación geológica; ¿podemos traducir esta frase diciendo que «el ritmo de producción de petróleo es mucho más rápido que su ritmo de formación»?

La expresión «el PIB crecerá el uno por ciento el próximo año» es quizá una expresión metafísica, pese a que es muy fácil verificar en la Contabilidad Nacional si las cifras del PIB (en términos «reales», que para los economistas significa descontando la inflación de los precios) han subido o han bajado. Estas cifras se calculan sumando los "valores añadidos" para todas las empresas y actividades económicas, es decir, los valores de las ventas menos los valores de las compras de inputs. Ahora bien, dentro de esta «producción», ¿se valora de forma adecuada la destrucción?

En los modelos de crecimiento económico, ¿qué significado puede tener la siguiente afirmación: «un aumento de la inversión supone un aumento de la producción»? Inversión Neta se define como aumento de la capacidad «productiva». Cuando los macroeconomistas hablan de "producción», dan un peso concreto a los distintos ingredientes de esta mezcla. ¿Se han marcado «bien» los precios de los recursos no renovables destruidos?

Al correlacionar Inversión Neta (privada y estatal) y aumentos de producción, se observa que últimamente aumenta la capacidad "productiva» (aunque lentamente) y casi no aumenta la «producción». En lenguaje de los economistas podemos hacer la siguiente proposición: «el estancamiento de la producción no se debe tanto a las deficiencias de la demanda efectiva como al incre- 
mento de la relación incremental capital/producto». Sin embargo, esta afirmación es tautológica, ya que si la producción está estancada y el stock de capital aumenta (medido según los cálculos de la Contabilidad Nacional), entonces aumenta, evidentemente, la relación incremental capital/producto. Para no ser tautológico, la proposición debería analizar el contenido de la inversión y de la producción.

Tanto la microeconomía como la macroeconomía se basan en el individualismo metodológico, aunque parezca que la macroeconomía cuando habla de relaciones entre magnitudes agregadas de la economía (el Producto Total, el Ingreso Total, el Consumo Total, el Ahorro y la Inversión Total) tenga otro enfoque. Se dice que la teoría macroeconómica necesita tomar el agente individual como típico o representativo de los demás, y afirmar que la humanidad, en conjunto, es tan racional como él. «Por ejemplo, el análisis de la inversión, del ahorro y de la preferencia por la liquidez que ocupa la mayor parte de la Teoría General de Keynes adopta precisamente esta forma. Para poder explicar el mantenimiento de los salarios bajos debido al interés de los capitalistas, como grupo, para que se mantengan bajos necesita demostrar que cada capitalista actúa racionalmente y, de tal manera, que su agregación produce este efecto. Antes de considerar a los sindicatos o a los accionistas como colectivos, los analiza como coaliciones de individuos, cada uno de los cuales está interesado en cumplir las reglas que los unen y en actuar conjuntamente» (Hahn y Hollis, p. 3). Por lo tanto, los movimientos macroeconómicos se explican como el resultado colectivo de las acciones individuales racionales. «Las razones pedagógicas por las que el economista puro empieza por el análisis micro reflejan también este profundísimo compromiso ontológico» (ibid.). Por ejemplo, si nos preguntamos a qué obedece el que los salarios no desciendan mucho a pesar del paro, enseguida se nos ocurren dos respuestas posibles y diferentes: la primera diría que los sindicatos consiguen mantener los salarios a pesar de no ser salarios de «equilibrio»; la otra explicación consistiría en buscar las bases individualistas, analizando la conducta de empresas y de trabajadores. La literatura sobre «contratos implícitos» (Okun, 1981; Tobin, 1983) explica que las empresas muchas veces mantienen a sus trabajadores, pagando salarios altos, porque contratar a otros les supondría costes de aprendizaje y sería necesario buscar el tipo idóneo de trabajador, etc. Se intenta fundamentar con argumentos microeconómicos (basados en el intercambio) los fenómenos macroeconómicos como la estabilidad de los salarios en época de crisis.

Keynes consideró la inflexibilidad de los salarios como un dato, sin recurrir a explicaciones basadas en la acción racional de individuos ni en la acción colectiva. El mismo Keynes procuró poner bases individualistas a otros fenómenos macroeconómicos; por ejemplo, al discutir la función agregada de consumo/ahorro, que se supone que la persona racional tenderá a ahorrar una mayor parte de sus ingresos a medida que aumentan éstos. En cambio, adop- 
taríamos un «colectivismo metodológico» si explicáramos la propensión al ahorro a la manera kaleckiana (donde la variable es la clase social) o si la relacionáramos con el ciclo de desarrollo de la familia, es decir, con la estructura demográfica, o si incluyéramos en la explicación normas sociales, como puede ser el sentido vebleriano de la imitación de los consumos ostentosos.

La teoría del crecimiento económico que los economistas utilizan es casi siempre keynesiana, desarrollada especialmente a partir de Harrod (1939). Hubo un economista (Ise, 1950, pp. 415-416) que señaló que la economía keynesiana dejaba de lado la cuestión de la disponibilidad de los recursos naturales. No obstante, la mayoría de los economistas pensaron que el keynesianismo se convertiría en una teoría del crecimiento a largo plazo. Por ejemplo, Arthur Okun, en su libro póstumo (1981), considera todavía que existe una «linea de tendencia de prosperidad» (p. 272) que sirve de punto de referencia para cuantificar las pérdidas en producción real que representa la crisis.

Es decir, existe una hipotética «línea de tendencia de prosperidad» que nos indica que la economía podría crecer, por ejemplo, el 3, el 4 o el 5 por 100 anual, o cualquier cantidad, ya que esta cifra, quiromántica, está basada en la idea de que si la inversión anual fuera un cierto porcentaje del PIB, si la relación Inversión/PIB fuera más o menos estable, entonces, si no faltara demanda efectiva, la economía seguiría su «línea de tendencia».

Okun quería analizar si la pérdida de producción en los años de crisis, por debajo de la «línea de tendencia», refleja adecuadamente el coste «social» de la crisis, en el sentido que los economistas utilizan el término «social», es decir, si hay costes y beneficios no capturados por los valores de mercado. La lista de posibles correcciones (p. 274) incluye el hecho de que «la mínima producción posible en los períodos de recesión y recuperación reducen el desgaste de los bienes de capital existentes y la extracción de recursos naturales no renovables, como los productos de las industrias mineras».

Una buena contabilidad debería compensar los recursos naturales no renovables que se utilizan en la producción en partidas de «amortización» que impidieran la disminución de la capacidad productiva. «Comerse» un pozo de petróleo se parece mucho a «comerse» un tractor, descapitalizándose, si olvidamos restar una partida de los ingresos por amortización. Ahora bien, Okun, al discutir la corrección pertinente al valor «social» de la disminución de crecimiento del PIB en época de crisis, debido a una utilización menor de los recursos no renovables, decía así: «Las cuentas nacionales no registran ninguna reducción por agotamiento de recursos no renovables, ya que el valor de los nuevos descubrimientos de recursos no renovables tampoco lo estima. El valor de las provisiones por agotamiento en las cuentas de resultados de las empresas supone menos de la mitad del uno por ciento del PIB, lo que significa que la corrección apropiada del coste social (de la crisis) a causa de un agotamiento más lento es trivial» (p. 275). 
Para entenderlo mejor, podríamos reflexionar sobre el siguiente ejemplo: supongamos una economía ganadera; las ovejas y las vacas producen crías que nos comemos, es el PIB. No es preciso deducir ninguna cantidad de ovejas y vacas que mueren de viejas, puesto que tampoco hemos tenido en cuenta en el PIB las crías que se integran en el rebaño. Es decir, las prácticas contables seguidas con los recursos no renovables suponen que estos recursos no son no renovables, sino renovables, como si fueran vacas $u$ ovejas. No es preciso amortizarlos, o en todo caso muy poco, porque se van haciendo descubrimientos. Si existen recursos no renovables, algún día se acabarán los descubrimientos de nuevos yacimientos.

Los economistas interpretan todo decrecimiento de la producción, e incluso todo crecimiento inferior a la «línea de tendencia», como la manifestación de una crisis. Sus protestas sobre la distribución (concretamente sobre la limitación de los salarios) no las realizan desde la perspectiva de repartir una producción real permanentemente disminuida, sino desde la perspectiva de "salir de la crisis». Cuando existe una deficiencia de demanda efectiva, que no permite utilizar completamente la capacidad productiva instalada ni la mano de obra disponible, el gasto complementario, desde una perspectiva a corto plazo, puede venir indiferentemente tanto del consumo extra de los asalariados como de las inversiones o de los ingresos de las exportaciones. La ideología que propone frenar los incrementos salariales para que aumente la inversión no es keynesianismo a corto plazo. Sin embargo, a largo plazo, es decir, considerando las variaciones en la capacidad productiva instalada y en la población activa, un gasto de inversión que, a corto plazo, activa la demanda permite, a largo plazo, ampliar la oferta si esta inversión es «productiva». Frenar el aumento de los salarios no es incompatible con un aumento de demanda efectiva si la inversión y las exportaciones aumentan lo suficiente; pero es, evidentemente, compatible con incrementos de la capacidad productiva si el efecto consiste en aumentar la inversión.

A menudo, las propuestas de frenar los salarios con «pactos sociales» (como las de Okun, Tobin y, a nivel de divulgación, Rohatyn en los Estados Unidos; la OCDE y otros en Europa) se hacen también con la intención de frenar la inflación. Una economía con crecimiento permite el consensus, sin que la desigualdad entre clases desaparezca. Cuando hay crisis económicas por el lado de la oferta (por ejemplo, cuando, como hemos visto en el caso brasileño, cada vez resulta energéticamente más caro disponer de energía), las ilusiones de crecimiento continuado pueden llevar a la inflación, ya que, como decía Soddy, se confunde la expansión de la capacidad de producción (expansión del capital físico) con la expansión de la deuda (del capital financiero). Al final, la inflación ya no sirve de lubrificante social, sino que introduce gran incertidumbre en los planes de inversión al aumentar las tasas de interés monetario. Los empresarios se endeudan sin saber cuánto realmente les tocará 
pagar después (ya que las tasas monetarias de interés contratadas pueden resultar altísimas si la inflación disminuye).

Por lo tanto, las políticas neocorporativistas se proponen muchas veces como objetivo manifiesto para la inflación. Su base teórica es la «curva de Phillips», que al principio era una «ley» puramente econométrica que indicaba que inflación y paro estaban inversamente relacionados. Cuando en la década de los setenta la inflación y el paro crecieron simultáneamente, se interpretó como un desplazamiento de la «curva de Phillips» motivado por la inclusión de las expectativas de inflación en las negociaciones salariales. El argumento corporativista consiste en reducir voluntariamente los aumentos salariales a fin de reducir las presiones sobre los costes y aumentar el empleo. Pero este argumento a corto plazo no aparece nunca solo: se añade siempre que la reducción de salarios tendrá efectos positivos sobre la inversión y, por lo tanto, sobre el crecimiento.

Desde el punto de vista metodológico, puede parecer que los hechos descritos por la «curva de Phillips» se prestan más a un análisis colectivo que individualista. Por ejemplo, la «curva de Phillips» no puede ser traducida fácilmente a lenguaje marxiano-kaleckiano: la inexistencia de un «ejército industrial de reserva» (en la década de los sesenta) favoreció que los sindicatos presionasen sobre los beneficios, presiones que con las estructuras oligopolíticas de mercado (o, lo que es lo mismo, con una teoría de la formación de precios industriales por mark-up sobre los costos variables en las empresas) pueden trasladarse a los precios. Este análisis podía adoptar fácilmente un lenguaje durkheimniano si la conclusión política que se saca no es la de permitir la agudización de un profit squeeze por medio del control legal de los precios, sino, al contrario, controlando los salarios por medio de acuerdos corporativos entre los grandes actores sociales. Desde ambos puntos de vista (políticamente opuestos), las unidades de análisis son colectivos sociales.

Al contrario, desde el punto de vista del individualismo metodológico, se ha dicho que «existen explicaciones semielaboradas de fenómenos sociales de gran escala (por ejemplo, la inflación) en términos de otros fenómenos sociales de gran escala (por ejemplo, el pleno empleo); sin embargo, no llegaremos a explicaciones fundamentales de estos fenómenos de gran escala hasta que no hayamos podido deducir una explicación a partir de proposiciones sobre las disposiciones, las creencias, los recursos y las interacciones de los individuos. (Los individuos pueden ser anónimos y se les puede atribuir únicamente disposiciones típicas)» (Watkins, 1959; cit. por Lukes, 1973). Es como decir (la comparación es de Lukes) que el individualista metodológico, con tal de explicar el funcionamiento del ejército, se centra en el estudio de las preferencias individuales de los soldados -0 del soldado típico-, con su curiosa disposición a obedecer órdenes.

De este modo, en época de desempleo, si los salarios no bajan «lo suficiente» para permitir, pace la «curva de Phillips», una reducción sustancial 
de la presión sobre los costos (por lo tanto, una reducción de la inflación), y si no bajan lo suficiente para permitir - a largo plazo- un aumento de la inversión que incremente la capacidad productiva, esto debe explicarse analizando decisiones racionales de obreros típicos y empresas típicas que maximicen o minimicen algo. Y, sin embargo, los «colectivistas metodológicos» utilizarían, quizá, las normas sociales del colectivo de trabajadores y del colectivo de capitalistas, el poder monopolístico en el mercado de los productos y hasta, incluso, conceptos como conciencia de clase y lucha de clases (cfr. Sawyer, 1982, para un enfoque kaleckeriano de la macroeconomía).

Durkheim (1902) hacía esta predicción: la división del trabajo crea conflictos que pueden ser funcionales para la estabilidad de la sociedad capitalista si la sociedad y el Estado se organizan de manera corporativista. Este corporativismo es compatible con la representación parlamentaria de base territorial por sufragio universal, complementada por la representación corporativa de diferentes intereses profesionales, que establezcan acuerdos para solucionar los conflictos derivados de una economía de mercado, de la división del trabajo, del individualismo "anónimo», es decir, desprovisto de las normas tradicionales de convivencia. Para Durkheim, hay hechos e instituciones sociales irreductibles a preferencias y decisiones individuales.

La concepción corporativista de la sociedad es diferente de la concepción liberal-individualista. La primera pone el énfasis en el aspecto social de las personas y en la armonización de los intereses de los diversos colectivos a los que pertenecen, por medio de negociaciones fuera del mercado. La segunda se expresa en un individualismo no sólo metodológico, sino ontológico, y cree en la armonización de los intereses individuales mediante la actuación de la «mano invisible» en el mercado. Los partidarios de los «pactos sociales» encajan mejor en la concepción corporativista, aunque muchos de ellos sean economistas.

Podríamos pensar también que para hacer macroeconomía no es necesario ninguna discusión metodológica previa, en el sentido que la macroeconomía puede establecer leyes puramente econométricas. Por ejemplo, el que las unidades básicas de análisis social sean los individuos o los colectivos puede parecer una cuestión superflua si pensamos en los estudios de Kuznets (1966) donde correlaciona aumentos del PIB y proporción de Inversión Neta (magnitudes sacadas de la Contabilidad Nacional). Otro ejemplo podría ser la extrapolación de los supuestos ciclos de Kondratiev.

Sin embargo, para establecer magnitudes de la Contabilidad Nacional necesitamos agregar inputs y productos y, por lo tanto, necesitamos darles valores. Los macroeconomistas no pueden, pues, prescindir de la microeconomía. La cuestión no consiste en explicar los fundamentos microeconómicos de las acciones de los individuos, ya que estas acciones posiblemente se expliquen mejor si los consideramos como miembros de colectivos sociales, del mismo 
modo que las peculiares acciones de los soldados se entienden mejor únicamente si entendemos los reglamentos y los castigos del ejército. La cuestión consiste en que la macroeconomía necesita precios para agregar magnitudes macroeconómicas, y los precios salen únicamente de la microeconomía.

En una economía ricardiana sencilla, con un solo producto, «trigo», que sirve también de semilla, podríamos dar el Producto Total, el Consumo, la Inversión (en forma de semilla), los Salarios, las Ganancias de los arrendatarios capitalistas y las Rentas de los terratenientes, todo en unidades de trigo. Además, podríamos suponer que de un año a otro año baja el Consumo y aumenta la Inversión (una parte mayor de la cosecha se utiliza como semilla); podríamos estudiar entonces cómo aumenta el Producto Total y calcular la Tasa de Rendimiento de la Inversión (una especie de Tasa de Interés), que presumiblemente ha compensado el sacrificio de Consumo actual a cambio de un aumento de Consumo posterior, sin derrochar, en este caso, ningún recurso no renovable.

Sin embargo, las Contabilidades Nacionales reales utilizan los precios, porque no hay otra manera de sumar productos heterogéneos. La macroeconomía tropieza, por lo tanto, con la cuestión de los precios de los recursos no renovables. No puede haber macroeconomía en las economías monetarias sin microeconomía crematística, porque la Contabilidad Nacional se hace con los precios, que son simplemente los del mercado o (en el caso de los recursos no renovables) quizá unos precios corregidos según costos de oportunidad ético-subjetivos de la utilización actual que sacrifica la utilización futura.

No obstante, se puede pensar que para analizar el reparto del Ingreso Total entre asalariados y capitalistas, por ejemplo, resulta más fructífero estudiar la lucha de clases (o la armonía de clases conseguida por medio de acuerdos corporativos) que recurrir al estudio de acciones individuales de intercambio. Esta perspectiva, que considera los colectivos como unidades básicas de análisis, lleva a recomendaciones, por ejemplo, sobre «políticas de rentas» con acuerdos entre gobierno, patronal y sindicatos a fin de frenar la inflación y de aumentar la inversión, lo cual puede llevar a un aumento de la producción (tanto a corto como a largo plazo). Se hacen llamadas a la «solidaridad nacional» (y no a la "mano invisible», de un lado, ni a la lucha de clases, del otro) para «salir de la crisis». Me parece que la ideología socialdemócrata ( $y$, por supuesto, eurocomunista) ha sido una mezcla de corporativismo durkheimniano (laico y no antiparlamentario) y de macroeconomía keynesiana.

El corporativismo socialdemócrata es, de todas maneras, anterior a la década de los treinta (Charles Maier, 1975). Pero la socialdemocracia nacida de la lucha de clases tiene un problema de legitimidad política si se declara corporativista y, por esta razón, le ha sido necesario apoyarse en la macroeconomía.

La consideración de los recursos no renovables origina dudas básicas sobre las definiciones de las magnitudes macroeconómicas («producción», por 
ejemplo) y, por lo tanto, daña a la ideología de la socialdemocracia corporativista, que quiere legitimar la desigualdad en espera del crecimiento, al cuestionar algo tan elemental como la manera de construir la Contabilidad Nacional.

(Traducido por Nuria Garreta.)

\section{BIBLIOGRAFIA}

Aguilar, Salvador: «El asociacionismo empresarial en la transición postfranquista», Crónica de Información Laboral, núms. 17-18, julio-agosto 1983.

Alemann, Ulich v., y Heinze, R. G. (eds.): Verbände und Staat. Vom Pluralismus zum Korporatismus, Opladen, 1979.

Amsden, Jon: Collective bargaining and class conflict in Spain, Weindenfeld \& Nicholson, Londres, 1971.

ANDERson, Charles: The political economy of modern Spain, Chicago U. P., 1970.

Aunós, Eduardo: La organización corporativa del trabajo, Consejo Superior de Trabajo, Comercio e Industria, Madrid, 1927.

Aznar, Severino: Estudios económico-sociales, Instituto de Estudios Políticos, Madrid, 1946 (prólogo de José Larraz).

AzPiazu, Joaquín (S. J.): El Estado corporativo, Ed. Navarra, Pamplona, 1937 (con bibliografía austríaca y alemana).

CAwson, Alan: «A preliminary bibliography of modern corporatism», Sussex Working Papers in Corporatism, núm. 1, abril 1983.

Connolly, W.: The Terms of Political Discourse, 2." ed., Martin Robertson, Oxford, 1983.

Diamant, Alfred: Austrian Catbolics and the First Republic, Princeton, 1960.

EstradÉ, A., y Casado, J. A.: «El nuevo corporativismo: una salida capitalista ante la crisis», Transición, Barcelona, núm. 14, noviembre 1979.

Fraga Iribarne, Manuel: «La reforma de la empresa», en El desarrollo político, Grijalbo, Barcelona, 1972.

Giner, S.: «España entre el viejo y el nuevo corporatismo», La Vanguardia, 29 abril 1982.

Giner, S., y Sevilla, E.: «Spain: from Corporatism to Corporatism», en Williams, A. (ed.): Southern Europe transformed, Harper \& Row, 1984.

Grenner, Karl Heinz: Wirtschaftsliberalismus und Katolische Denkens, J. P. Bachem, Colonia, 1967 (Adam Müller, Baader, Ketteler, Reichensperger, Hitze, Pesch).

Gulick, Charles A.: Austria from Habsburg to Hitler, University of California Press, Berkeley, 1948.

HayeK, F. A. v.: The constitution of liberty, Routledge \& Kegan Paul, Londres, 1960.

Jones, Aubrey: The New Intlation, Penguin Books, 1973.

KastendieK, Hans: «Neokorporatismus?», Prokla, núm. 38, 1980.

LANG, W.: «Spanien nach Franco: vom autoritären zum liberalen Korporatismus?», en AlemanN, Ulrich v. (ed.): Neokorporatismus, Campus Verlag, Frankfurt, 1981.

Le h mbruch, G., y Sch mitter, Ph. (eds.): Patterns of Corporatist Policy Making, Sage, Londres, 1982.

LINZ, Juan: "A century of politics and interest in Spain», en BERGER, S. (ed.): Organizing interests in Western Europe, Cambridge U. P.

MaIER, Charles: Recasting bourgeois Europe, Princeton, 1975.

Maravall, J. M.: La politica de la transición, Taurus, Madrid, 1982.

Martín-Artajo, Alberto, y Cuervo, Máximo: Doctrina social católica de León XIII y Pio XI, Labor, Barcelona, 1978 (prólogo de Angel Herrera Oria).

Martínez Alier, J.: «Notas sobre el franquismo», Papers. Revista de Sociología, núm. 8, Barcelona, 1978.

- «El Pacto de la Moncloa. La lucha sindical y el nuevo corporativismo», Cuadernos de Ruedo Ibérico, núms. 58-60, 1977.

- «El viejo y el nuevo corporativismo», El País, 5 diciembre 1981. 
Moyano, Eduardo, y Pérez Yruela, Manuel: «El estado de la cuestión en el debate neocorporativista» (Ms., 1984).

Moyano, Eduardo: «Corporatismo y agricultura» (tesis doctoral, Esc. Ing. Agr., Universidad de Córdoba, 1983).

Müller, Alberto, y AzPIAzu, Joaquin: La politica corporativa. Ensayo de organización corporativa, Razón y Fe, Madrid, 1935.

Nell-Breuning, Otto: Die soziale Enzyklika, Katholische Tag Verlag, Colonia, 1932.

PÉREz DíAz, Víctor: "Políticas económicas y pautas sociales en la España de la transición: la doble cara del neocorporatismo» (Ms., 1984).

- «Orientaciones políticas de los obreros españoles hoy», Sistema, núms. 29-30, 1979.

Pike, F., y Stritch, T. (eds.): The New Corporatism. Social Political Structures in the Iberian World, Notre Dame, 1974.

Pradera, Víctor: El Estado nuevo (1937), 3." ed., Cultura Española, Madrid, 1941 (prólogo de J. M." Pemán).

RocA, Jordi: "Els pactes socials: cap a un nou corporativisme? El cas de l'Estat espanyol, 1978-83» (tesina de licenciatura, UAB, Bellaterra, Barcelona, 1984).

Ro hatyn, Felix G.: «Time for a Change», New York Review of Books, 18 agosto 1983.

Sáez Alba, A.: La Asociación Católica Nacional de Propagandistas, Ruedo Ibérico, París, 1974.

Sс н ÜTZ, Roland: «Verbände und Verbandsmacht in Spanien. Neokorporative Strukturen bei der Artikulation und Repräsentation von Gruppeninteressen in Spanien" (Ms., octubre 1983).

Secretariado de la Junta Nacional de Semanas Sociales: Hacia una más justa distribución de la riqueza (IX Semana), Madrid, 1950 (Azpiazu, Aznar, Herrera Oria y el economista Torres Martínez y otros).

- El trabajo (XII Semana), Madrid, 1952 (Larraz, Fraga, G. Menéndez-Reigada, los economistas Inza y Fuentes Quintana y otros).

SH ONFIELD, A.: Modern capttalism, Oxford U. P., 1965.

WIARDA, H. J.: «Corporatism and Development in the Iberic-Latin World», en Prke y STRITCH, 1974. 